\title{
Manifestações cutâneas da infecção e das doenças relacionadas ao vírus linfotrópico de células T humanas do tipo $1^{*}$ Cutaneous manifestations in buman T-cell lymphotropic virus type 1 infection
}

\author{
aMarcelo Grossi Araújo ${ }^{1}$ \\ Anna Bárbara F. Carneiro-Proietti ${ }^{3}$ \\ Antonio Carlos M. Guedes ${ }^{5}$
}

\author{
Denise Utsch Gonçalves ${ }^{2}$ \\ Fernando Augusto Proietti ${ }^{4}$
}

\begin{abstract}
Resumo: O vírus linfotrópico de células T humanas tipo 1 (HTLV-1) é um retrovírus encontrado em todo o mundo e, no Brasil, tem distribuição heterogênea com várias regiões consideradas de alta prevalência. Está relacionado com doenças graves e/ou incapacitantes, como a leucemia/linfoma de células T do adulto, com a doença neurológica conhecida como mielopatia associada ao HTLV-1/paraparesia espástica tropical, com a uveíte associada ao HTLV-1 e com a dermatite infecciosa. O risco para o aparecimento dessas doenças depende, principalmente, de fatores genéticos, da forma como a infecção foi adquirida e da carga proviral. Estima-se que até $10 \%$ dos infectados possam desenvolver alguma doença relacionada ao vírus ao longo da vida. O comprometimento da pele tem sido descrito tanto nas doenças relacionadas ao HTLV-1 quanto nos indivíduos portadores assintomáticos. Vários mecanismos são propostos para explicar as lesões da pele, seja pela presença direta do vírus em células, pela imunossupressão ou por resposta inflamatória que a infecção pelo vírus poderia desencadear. Dentre as manifestações dermatológicas mais freqüentes destacam-se a xerose, as dermatofitoses e as infecções bacterianas recorrentes. Neste artigo são revistos os principais aspectos referentes à infecção e às doenças relacionadas ao HTLV1, com ênfase na discussão das manifestações dermatológicas observadas nesse contexto.

Palavras-chave: Infecções por HTLV-I; Infecções por HTLV-I/complicações; Linfoma cutâneo de células T; Manifestações cutâneas; Paraparesia tropical espástica; Pele; Vírus linfotrópico de células T humanas tipo 1
\end{abstract}

\begin{abstract}
Human T lymphotropic virus type 1 (HTLV-1) has beterogenous distribution worldwide and, in Brazil, there are high prevalence areas. HTLV-1 has been associated to severe diseases, such as adult T cell leukaemia/lymphoma, HTLV-1 associated myelopabthy/tropical spastic paraparesis, HTLV-1 associated uveitis and HTLV-1 associated infective dermatitis. Genetics, proviral load and infection route are related to disease risk along life. The lifetime risk to develop HTLV-1 related diseases may be close to 10\%. Skin lesions are known to occur in the course of HTLV-1 related diseases and also in asymptomatic carriers. Xerosis, dermatophytosis and recurrent infections are among the most common found skin diseases. In this paper the authors reviewed the major associated diseases and aspects of the HTLV-1 infection itself, with emphasis on skin manifestations in the context.

Keywords : HTLV-I infections; HTLV-I infections/complications; Human T-lymphotropic virus 1; Lymphoma, T-cell, cutaneous; Paraparesis, tropical spastic; Skin; Skin manifestations
\end{abstract}

\footnotetext{
Aprovado pelo Conselho Editorial e aceito para publicação em 29.09.2008

* Trabalho realizado no Programa de Pós-Graduação em Ciências Aplicadas à Saúde do Adulto da Faculdade de Medicina da Universidade Federal de Minas Gerais (UFMG) - Belo Horizonte (MG), Brasil.

Conflito de interesse: Nenhum.

Suporte financeiro: O trabalho é parte de projeto desenvolvido pelo GIPH (Grupo Interdisciplinar de Pesquisas em HTLV), com recursos da Fapemig (Fundação de Amparo à Pesquisa do Estado de Minas Gerais), Fundação Hemominas e CNPq

Doutorando do Programa de Pós-Graduação em Ciências Aplicadas à Saúde do Adulto e professor-assistente do Departamento de Clínica Médica da Faculdade de Medicina da Universidade Federal de Minas Gerais (UFMG) - Belo Horizonte (MG), Brasil.

Professora doutora do Departamento de Oftalmologia, Otorrinolaringologia e Fonoaudiologia da Faculdade de Medicina da Universidade Federal de Minas Gerais (UFMG) - Belo Horizonte (MG), Brasil.

Médica hematologista, doutora, presidente da Fundação Hemominas de Belo Horizonte e coordenadora do GPIH (Grupo Interdisciplinar de Pesquisas em HTLV) - Belo Horizonte (MG), Brasil.

Professor doutor do Departamento de Medicina Preventiva e Social da Faculdade de Medicina da Universidade Federal de Minas Gerais (UFMG) - Belo Horizonte (MG), Brasil.

Professor doutor do Departamento de Clínica Médica da Faculdade de Medicina da Universidade Federal de Minas Gerais (UFMG) - Belo Horizonte (MG), Brasil.

(C)2008 by Anais Brasileiros de Dermatologia
} 


\section{INTRODUÇÃO}

$\mathrm{O}$ vírus linfotrópico de células $\mathrm{T}$ humanas tipo 1 (HTLV-1 Human T lymphotropic virus type 1) é retrovírus da família Retroviridae, subfamília Orthoretrovirinae e gênero Deltaretrovirus. ${ }^{1}$ Primeiro retrovírus associado a doença humana, teve sua ligação com leucemia/linfoma de células $\mathrm{T}$ do adulto (ATL) definitivamente estabelecida em $1980 .{ }^{2}$ Em seguida, foi associado a doença neurológica (paraparesia espástica tropical/mielopatia associada ao HTLV-1 - HAM/TSP), ${ }^{3}$ doença ocular (uveíte associada ao HTLV-1 - HAU) ${ }^{4}$ e dermatite infecciosa (DI). ${ }^{5}$ Várias outras associações foram descritas, ainda sem evidências conclusivas. As duas condições mais importantes ATL e HAM/TSP são encontradas em todas as regióes endêmicas, embora com prevalência e incidência variáveis. A DI tem associação definitivamente estabelecida com a infecção pelo HTLV-1 na população infantil. No adulto, a DI é admitida como associação provável. ${ }^{6}$ A maioria dos infectados pelo HTLV-1 permanece assintomática, mas até $10 \%$ desses pacientes podem desenvolver alguma das doenças relacionadas ao vírus, ao longo da vida.

Muitas alterações de pele têm sido descritas, tanto em indivíduos infectados assintomáticos quanto naqueles que desenvolveram doença associada ao HTLV-1. ${ }^{8}$ Dermatologistas devem estar familiarizados com essas alterações, pois seu reconhecimento pode levar ao diagnóstico da infecção e à adoção de medidas importantes no plano individual, familiar e coletivo.

Esta revisão abordará os aspectos gerais da infecção pelo HTLV-1, com ênfase no estado atual do conhecimento das alterações dermatológicas.

\section{EPIDEMIOLOGIA}

A presença do HTLV-1 está bem estabelecida em regiões do Japão, Caribe, América do Sul e África, com prevalência muito variável entre elas. Embora não se conheça o número exato, estima-se entre 15 e 20 milhões de infectados no mundo. ${ }^{6}$ Admite-se que o Brasil possa ter o maior número absoluto de casos de infecção pelo HTLV (cerca de 2,5 milhões), considerando população e taxas de prevalência detectadas." ${ }^{90}$ Contudo, considera-se que sua distribuição seja heterogênea; estudo de triagem em candidatos à doação de sangue mostrou prevalência maior no Nordeste, Norte e Sudeste. As taxas variaram de 0,4/1.000 em Florianópolis a 10/1.000 em São Luís. ${ }^{10}$

A variabilidade da seqüência do HTLV-1 intra e inter-individual é baixa, e acredita-se que isso seja decorrente de sua maneira de disseminação, que se dá mais à custa da transmissão do provírus nos linfócitos infectados do que por meio de partículas virais, como ocorre com o vírus da imunodeficiência humana (HIV) ${ }^{11}$ Após breve período de replicação mediada pela enzima transcriptase reversa no início da infecção, o aumento da carga proviral se dá por expansão clonal de linfócitos infectados e, muito menos, pela produção de virions. ${ }^{7,11}$

Os vários subtipos do HTLV-1 são descritos de acordo com as diferenças da seqüência do DNA proviral do gene env e da região LTR (long terminal repeat). ${ }^{1}$ Os subtipos do HTLV-1 incluem o A, chamado cosmopolita, descrito no Japão e na maior parte das áreas endêmicas do mundo, o B, D e F da África Central, o E da África do Sul e Central, e o C da Melanésia. As seqüências do HTLV-1 podem ser comparadas àquelas do vírus de células $\mathrm{T}$ do símio (STLV-I), encontrada em primatas. A semelhança das seqüências do vírus de primatas com as observadas em humanos sugere a possibilidade de ocorrência de infecção do símio para o homem e vice-versa, e a possível origem do HTLV-1 na África. ${ }^{12}$

As formas de transmissão são bem conhecidas, embora existam lacunas no conhecimento das taxas de transmissão e a respeito de fatores promotores ou inibidores de algumas vias de transmissão. ${ }^{6}{ }^{13}$ Vários comportamentos e tipos de exposição são relacionados à soropositividade para o HTLV-1 correspondendo às formas de transmissão conhecidas: mãe-filho, especialmente pela amamentação; via relação sexual; e via parenteral, pela transfusão de componentes de sangue infectado ou compartilhamento de agulhas entre usuários de drogas endovenosas. As áreas endêmicas em regiões tropicais e subtropicais, a infecção em aglomerados familiares ou vizinhos e o declínio da soropositividade em meio a imigrantes de áreas endêmicas para não endêmicas sugerem co-fatores biológicos ou comportamentais influenciando a transmissão do HTLV-1. ${ }^{6,14}$ A transmissão por via endovenosa é a mais eficiente, ocorrendo soroconversão em 40-60\% dos expostos ao sangue contaminado, especialmente sangue total e seus componentes celulares, como concentrado de hemácias e plaquetas. A soroconversão se dá, em média, entre 51 e 65 dias após exposição. ${ }^{15} \mathrm{~A}$ adoção da triagem em bancos de sangue em vários países reduziu o número de novas infecçóes na população em geral. ${ }^{7}$ A transmissão materno-infantil ocorre em 20-36\% dos expostos e parece estar relacionada à carga materna proviral, altos títulos de anticorpos e tempo de aleitamento prolongado. A transmissão sexual, como em outras infecções sexualmente transmitidas, relaciona-se com sexo sem proteção, múltiplos parceiros, úlceras genitais e sexo pago. A maior parte dos estudos transversais sugere maior eficiência da transmissão na direção homem-mulher. ${ }^{6} \mathrm{O}$ compartilhamento de agulhas contaminadas entre usuários de drogas endovenosas é outra forma importante de transmissão. ${ }^{6,14}$ 
Em áreas endêmicas ou não, as taxas de soroprevalência são fortemente dependentes de idade e sexo, aumentando com a idade e predominando no sexo feminino. Várias explicações surgem para o efeito da idade: aumento da soroconversão ao longo da vida, efeito idade na coorte pela redução do número de novas infecções e possível soroconversão tardia. Na mulher, fatores hormonais ou maior eficiência da transmissão homem-mulher poderiam explicar a maior soroprevalência. ${ }^{6}$ Pode-se supor que fatores ligados ao comportamento das populações, como prática de sexo sem proteção ou amamentação prolongada, tenham interferência na prevalência da infecção. $O$ padrão de distribuição por sexo e idade se mantém em países ou regiões com situações epidemiológicas completamente diferentes. $^{6}$

\section{DIAGNÓSTICO LABORATORIAL DA INFECÇÃO}

O diagnóstico laboratorial da infecção pelo HTLV se baseia na detecção de anticorpos específicos contra o vírus ou na amplificação de seu material genético pela técnica de reação em cadeia da polimerase (PCR).

Os testes sorológicos são os mais utilizados e podem ser classificados em de triagem e confirmatórios. O mais utilizado na triagem é o ensaio imunoenzimático, que possui boa sensibilidade, sem discriminar, entretanto, se a infecção é por HTLV-1 ou 2, em virtude da semelhança entre as proteínas estruturais dos dois vírus. Quando o teste de triagem for reativo deverá ser repetido e, se confirmada sua positividade, será realizado teste confirmatório. Entre esses o mais utilizado é o Western Blot (WB), que permite a diferenciação entre os tipos 1 e 2 . Existe ainda a possibilidade de a amostra apontar reatividade em algumas bandas, sem completar o critério de positividade, quando seu resultado será considerado indeterminado. Esse tipo de resultado pode decorrer do tipo de teste de triagem utilizado (aumentando os falso-positivos), de a infecção ser pelo HTLV-2 e de imunossupressão, entre outras causas. Outros testes confirmatórios seriam o imunoblot e a imunofluorescência indireta (IFI). A PCR é considerada o método mais adequado para o diagnóstico molecular do HTLV, em função de sua característica de se integrar ao DNA da célula (provírus). Essa técnica não só detecta, mas pode quantificar o número de cópias presentes na amostra. Vários algorítmos são propostos, e as técnicas são descritas em artigos e livros da área., 16

\section{MANIFESTAÇÕES CUTÂNEAS}

Lesões e doenças dermatológicas têm sido observadas no curso da infecção pelo HTLV-1 desde que se estabeleceu a relação desse retrovírus com ATL e com HAM/ TSP. $^{17}$ A ocorrência de dermatoses em indivíduos infectados pelo HTLV-1 sem doença relacionada (ATL e HAM /TSP) foi descrita. ${ }^{18}$

Embora várias classificações já tenham sido propostas para o entendimento das manifestações cutâneas, nenhuma delas pode ser considerada definitiva. Muitos aspectos de alterações dermatológicas possivelmente relacionadas ao HTLV-1 não estão esclarecidos, e muitas delas carecem de evidências para ser definitivamente associadas à infecção. ${ }^{6,17}$ Algumas proposições para seu entendimento já foram feitas. La Grenade $^{19}$ as divide em três grupos: lesões relacionadas às doenças causadas pelo HTLV-1, lesões relacionadas à imunossupressão e lesões inespecíficas. Nobre e colaboradores ${ }^{17}$ propõem classificação que considera possíveis mecanismos envolvidos em sua patogênese. Assim seriam: lesões diretamente causadas por células infectadas pelo HTLV-1 na pele (neoplásicas e não neoplásicas); lesões indiretamente causadas por células infectadas pelo HTLV-1 na pele (esse grupo inclui além das alterações por imunossupressão e por alterações neurológicas, lesões por produção de citocinas e aquelas por outros mecanismos indiretos) e lesões inespecíficas.

Neste artigo os autores destacam a dermatite infecciosa, cuja relação com o HTLV-1 está estabeleci$\mathrm{da}$, e discutem as demais dermatoses, relacionando-as com os quadros de doença (ATL, HAM/TSP) ou infecção assintomática pelo HTLV-1.

\section{Dermatite infecciosa}

A DI foi descrita na Jamaica por Sweet em $1966^{20}$ e foi definitivamente associada à infecção pelo HTLV-1 em 1990 por La Grenade e colaboradores. ${ }^{5}$ É doença da infância que se manifesta geralmente depois dos 18 meses, embora haja relato em lactentes mais jovens. ${ }^{21,22}$ Recentemente foram descritos os primeiros casos com início na vida adulta. ${ }^{23} \mathrm{~A}$ maior parte dos casos ocorre na Jamaica, ${ }^{24}$ no Brasil e, em menor número, no Peru, Senegal e em Trinidad e Tobago. ${ }^{25}{ }^{26}$ No Japão, país com elevada prevalência da infecção pelo HTLV-1, foram relatados poucos casos da DI. Fatores genéticos ou socioeconômicos poderiam ser responsáveis por essa observação. ${ }^{6,26}$ No Brasil, o primeiro caso foi relatado no Rio de Janeiro, ${ }^{27}$ mas a maior casuística é proveniente de Salvador, na Bahia. ${ }^{25}$

A manifestação clínica é de dermatite eczematosa que compromete o couro cabeludo, pescoço, orelha externa (especialmente as áreas retroauriculares), axilas e virilhas. ${ }^{26}$ A localização nas fossas antecubitais e poplíteas foi descrita. ${ }^{25}$ Lesões eritêmato-descamativas ao redor das narinas, associadas à presença de descarga nasal fluida e crostas nas fossas nasais anteriores são descritas. O achado de blefaroconjuntivite é freqüente. Pápulas foliculares, lesões eritêmato-descamativas e pústulas podem ser observadas nas áreas com- 
prometidas. ${ }^{22,26}$ As culturas obtidas de material das fossas nasais anteriores ou pele são positivas para Staphylococcus aureus e/ou estreptococos $\beta$ hemolíti$\cos ^{25} \mathrm{Em}$ sua evolução são características a resposta rápida aos antibióticos e a recidiva quando de sua suspensão. Entretanto, foram observadas recidivas esporádicas e desaparecimento do quadro em alguns pacientes durante seu acompanhamento. ${ }^{25}$

Os critérios para o diagnóstico dessa afecção foram estabelecidos por La Grenade e colaboradores em $1998^{24}$ (Quadro 1).

O diagnóstico diferencial com outros eczemas deve ser feito, especialmente com a dermatite atópica (DA) e dermatite seborréica (DS) (Figura 1). A DA pode ocorrer em crianças soropositivas para o HTLV-1, e a DS já foi descrita em adultos e crianças infectados pelo HTLV-1 ${ }^{18,28}$ (Figura 2). As lesões da DI têm morfologia e distribuição semelhantes àquelas da DA, mas são mais exuberantes, exsudativas e fétidas, além de mostrar infecção evidente. Crostas nas narinas, fissuras retroauriculares e blefaroconjuntivite são encontradas na DI, e o prurido na DA tende a ser mais intenso. ${ }^{25}$ A DS mostra lesões com morfologia diferente da DI, além de ser rara na infância, a não ser na forma transitória do lactente. ${ }^{25} \mathrm{~A}$ boa resposta à sulfametoxazol-trimetoprim na DI é outro ponto para diferenciála da DA e da DS. ${ }^{25,26}$ O uso prolongado e repetido dessa medicação é recomendado para o controle da DI. ${ }^{25} \mathrm{O}$ exame histopatológico exibe alterações vistas em outros eczemas, embora elementos sugestivos de micose fungóide em placas possam ser encontrados em alguns casos. ${ }^{29}$ Estudo de imuno-histoquímica revelou predominância de $\mathrm{CD} 8+$ na pele e pequeno percentual de células com grânulos citotóxicos, suge- rindo que a maior parte dos linfócitos CD8+ não é ativada, diferente do que ocorre na DA e na DS. ${ }^{29}$

A DI está associada com o desenvolvimento futuro de HAM/TSP e de ATL, ${ }^{26,30-32}$ por isso recomenda-se o acompanhamento clínico e neurológico de crianças que a apresentem.

A sorologia para o HTLV-1 deve ser pesquisada em crianças e adolescentes com formas graves e resistentes de eczemas. ${ }^{26}$

\section{Dermatoses e leucemia/linfoma de células $\mathbf{T}$ do adulto (ATL)}

A ATL é forma grave de leucemia/linfoma relacionada ao HTLV-1, tem prognóstico reservado e não responde bem aos tratamentos quimioterápicos convencionais. ${ }^{33} \mathrm{Em}$ sua gênese a proteína Tax tem papel determinante. ${ }^{7}$ A estrutura genômica do HTLV-1 tem região denominada $\mathrm{pX}$, que faz a codificação para proteínas essenciais (Tax e Rex) e acessórias (p12, p13, p30), participantes da regulação da replicação viral e proliferação de células infectadas. ${ }^{7,34}$ A proteína Tax é conhecida por seu efeito marcante na proliferação celular, através da ativação de fatores da transcrição celular, como NFkB, AP-1, CREB e SRF, e ainda por sua capacidade de inibir a atividade funcional de fatores supressores de tumores como o p53, Rb e hDLG. ${ }^{34}$ Sua ligação direta com as quinases ciclino-dependentes e MAD1 leva à instabilidade cromossômica e desregulação do ciclo celular. Como resultado inibe a apoptose e leva à proliferação celular que resulta na transformação maligna das células. ${ }^{7,34}$

As manifestações cutâneas na ATL devem ser diferenciadas de várias dermatoses, de acordo com os tipos de lesões elementares predominantes. O diag-

QuADRo 1: Critérios diagnósticos para dermatite infecciosa

\section{CRITÉRIOS MAIORES}

1. Eczema do couro cabeludo, axilas, virilhas, ouvido externo, região retroauricular, pálpebras, região perinasal e/ou pescoço

2. Rinorréia crônica sem outros sinais de rinite e/ou lesões crostosas no vestíbulo nasal

3. Dermatite crônica recidivante com resposta imediata à antibioticoterapia e recidiva após sua suspensão

4. Início precoce na infância

5. Soropositividade para o HTLV-1

Obrigatória a presença dos itens 1, 2 e 5, e pelo menos dois locais do primeiro item devem estar afetados

\section{CRITÉRIOS MENORES}

1. Culturas positivas para Staphylococcus aureus e estreptococos $\beta$ - hemolíticos na pele ou fossas nasais

2. Erupção micropapulosa generalizada

4. Linfadenopatias generalizadas

5. Aumento na velocidade de hemossedimentação

6. Hipergamaglobulinemia IgD e IgE

7. Aumento de CD4 e CD8 e da relação CD4/CD8 


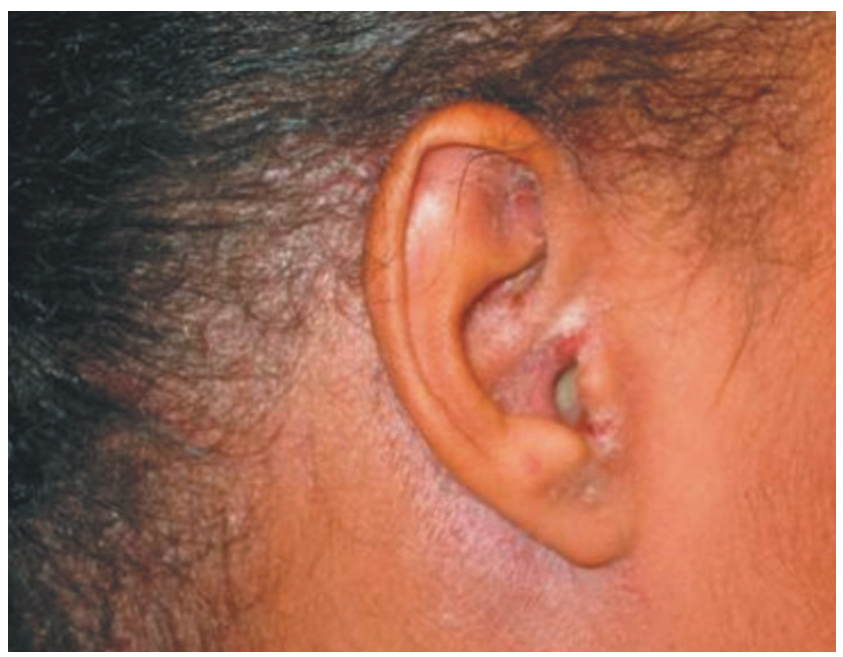

Figura 1: Dermatite infecciosa: eritema e descamação na região auricular, com secreção purulenta

nóstico diferencial com a micose fungóide (MF) e outros linfomas cutâneos (LC) sempre deve ser feito, e os critérios para isso são bem definidos. ${ }^{35}$ Entretanto, existem controvérsias sobre a relação dessas entidades. ${ }^{36}$ Embora vários estudos tenham demonstrado positividade para Tax, tanto em pacientes com LC como em familiares, outros autores não reproduzem resultados semelhantes, incluindo estudos de vários tipos de LC. ${ }^{36-43}$ Recentemente, soropositividade para anticorpos contra gag e env do HTLV-1 foi descrita em $52 \%$ de um grupo de pacientes estudados, com diagnóstico de $\mathrm{MF}^{36}$ Entretanto, o material genético do vírus foi encontrado na pele de apenas dois pacientes. Diferenças nos testes diagnósticos e baixo número de cópias são aventados como possíveis explicações. ${ }^{36}$

O país com maior número de casos conhecidos de ATL é o Japão, embora essa leucemia tenha sido descrita nas demais áreas endêmicas para o HTLV-1. ${ }^{6}$ Sua real incidência é desconhecida no Brasil ${ }^{44}$ e possivelmente em outras regiões, devido a fatores tais como seu curso rápido, dificuldade para diferenciá-la de outras doenças, desconhecimento por parte dos profissionais da saúde e carência de recursos para utilização de técnicas necessárias para seu diagnóstico correto em regiões menos desenvolvidas. ${ }^{6}$

No Brasil, ATL é freqüentemente diagnosticada entre as doenças linfoproliferativas em vários estados brasileiros. ${ }^{45,46}$ Trata-se de linfoma de células T periféricas, e a pele é freqüentemente comprometida. ${ }^{47}$ Embora não seja obrigatório, o comprometimento da pele ocorre em percentuais variáveis segundo o tipo de manifestação da ATL. ${ }^{48} \mathrm{O}$ comprometimento cutâneo ocorre entre 43 e $72 \%,{ }^{47}$ tendo variado de 30 a $73 \%$ em série brasileira. ${ }^{48}$

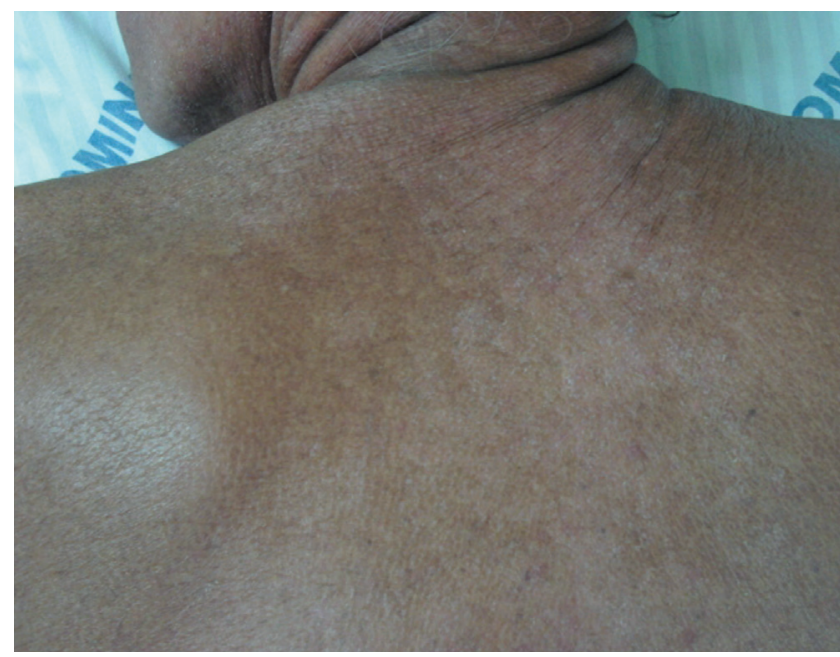

Figura 2: Dermatite seborréica: eritema e descamação - detalhe do dorso em indivíduo soropositivo assintomático

Estima-se que, dos infectados pelo HTLV-1, apenas de um a 5\% desenvolvem ATL. O tipo de doença associada ao HTLV-1 possivelmente depende de fatores genéticos do hospedeiro, incluindo os haplótipos do HLA que determinariam a suscetibilidade à infecção, a diferença das respostas específicas da células T e a carga proviral, e de fatores ambientais (modo de transmissão, dose do inóculo viral, idade, outras infecções). ${ }^{6,34,49}$ Admite-se que a transmissão vertical, principalmente pelo aleitamento materno, esteja relacionada ao risco futuro para desenvolvimento da ATL. ${ }^{6}$ Estudo brasileiro mostrou também a importância do aleitamento por amas-de-leite na transmissão do HTLV-1 e no desenvolvimento de ATL em agrupamentos familiares de pacientes diagnosticados com ATL. ${ }^{46}$ Casos de ATL pós-tranfusionais são raros. ${ }^{33}$ Trata-se de doença que ocorre na idade adulta, embora existam casos descritos na infância e adolescência. ${ }^{26,31,50}$ Admite-se que a infecção crônica e recorrente por Strongyloides stercoralis observada em muitos indivíduos infectados pelo HTLV-1 poderia levar à expansão clonal de linfócitos e ao aparecimento da ATL. ${ }^{51}$ Em crianças com diagnóstico de DI, a estrongiloidíase associada e a própria DI poderiam ser fatores relacionados ao aparecimento da ATL. ${ }^{25,26}$ Em adultos a história de eczema crônico na infância foi descrita ${ }^{52}$ assim como quadro clínico indistinguível da DI em paciente com a forma indolente da ATL. ${ }^{21}$ A idade média da manifestação da doença no Brasil e Jamaica é cerca de 10 anos inferior àquela observada no Japão, que se situa ao redor dos 60 anos. $^{26,33,44}$ Diferenças na apresentação clínica também são descritas, e as razões para tal são desconhecidas, admitindo-se que fatores ligados à patogênese possam estar implicados. ${ }^{6,33}$ 
As células da ATL expressam fenótipo T CD3+ CD4+ e CD8-, são CD25 positivas e induzem imunossupressão, características de células $\mathrm{T}$ reguladoras (Treg). Expressam vários genes de células Treg entre os quais o FoxP3 em mais de 50\% dos pacientes com ATL ${ }^{34,47}$ A expressão de receptores para quimiocinas e moléculas de adesão mostra diferenças nas lesões cutâneas e nos infiltrados de células tumorais em órgãos linfóides, sugerindo que a expressão dessas moléculas tenha papel fundamental na definição do órgão-alvo em cada tipo de ATL. ${ }^{34}$

As manifestações cutâneas podem ser decorrentes da infiltração cutânea pela neoplasia ou de alterações inflamatórias reativas à ATL. Como se observa em outras doenças linfoproliferativas, na infecção pelo vírus da imunodeficiência humana adquirida ou mesmo na hanseníase virchowiana, o prurido, a xerose e a ictiose adquirida podem ser sinais ou sintomas prodrômicos e nesse contexto devem ser valorizados. ${ }^{17}$, 19, 35 Dermatoses relacionadas à imunossupressão, tais como a escabiose crostosa, herpes-zóster disseminado e infecções fúngicas atípicas, são descritas. ${ }^{17,53,54}$

Os critérios para o diagnóstico da ATL podem assim ser sumarizados: presença de anticorpos antiHTLV-1, prova da integração monoclonal de segmento proviral do HTLV-1 em células tumorais, prova histológica ou citológica da presença de células malignas linfóides com antígenos de superfície da linhagem $\mathrm{T}$ (CD2, CD3 CD4+) e CD25+, presença de linfócitos anormais no sangue periférico (células com núcleos convolutos ou flower cells - exceção para o subtipo linfoma - e linfócitos pequenos com núcleos lobulados). ${ }^{33}$ Outras manifestações clínicas e laboratoriais, como as lesões de pele e hipercalcemia, são pontuadas em critérios de probabilidade do diagnóstico. ${ }^{55} \mathrm{O}$ espectro da ATL engloba os tipos agudo, linfoma, crônico, smouldering (indolente). A forma aguda predomina, enquanto as formas crônicas e cutâneas primárias seriam mais observadas no Japão em função do seu reconhecimento e diagnóstico mais precoces. ${ }^{6}$

$\mathrm{O}$ quadro clínico é polimorfo, e, diferente dos outros linfomas de células T não relacionados ao HTLV1 que podem comprometer unicamente a pele, na ATL as lesões cutâneas são freqüentemente associadas ao comprometimento de órgãos internos,$^{48}$ exceção para a forma cutânea primária associada ao HTLV-1. ${ }^{47}$

$\mathrm{Na}$ forma subaguda, indolente ou pré-leucêmica (smouldering) as lesões de pele geralmente constituem a primeira manifestação clínica, e podem preceder por meses ou anos a fase leucêmica aguda. As lesões podem assemelhar-se àquelas observadas na $\mathrm{MF}^{56} \mathrm{e}$ em outras formas da ATL, mas freqüentemente são inespecíficas e respondem ao corticóide tópico. ${ }^{48}$ No Brasil, lesões cutâneas foram encontradas em $67 \%$ dos casos $;^{48}$ na forma aguda, foram descritas em $60 \%$ dos casos,${ }^{48}$ com predominância de lesões papulosas e nodulares. ${ }^{17} \mathrm{~A}$ forma crônica foi a que teve maior percentual de casos com lesões de pele (73\%) na casuística brasileira. ${ }^{48} \mathrm{O}$ quadro clínico é arrastado, tem semelhança com a MF, e nele podem ser observadas placas eritêmato-edematosas e eritrodermia. ${ }^{17,56}$

A forma caracterizada como linfoma foi a que teve menor percentual de comprometimento cutâneo (30\%); $;^{48}$ entretanto, é a que tem manifestações mais exuberantes, com lesões extensas do tipo placas que tendem a se infiltrar formando nódulos e tumorações, além da presença de eritrodermia. ${ }^{17}$ Lesões purpúricas cujo mecanismo é desconhecido, mas não relacionadas à trombocitopenia, já foram descritas em oito pacientes no Japão. ${ }^{57} \mathrm{Em}$ um caso relatado, os autores admitem que as lesões sejam específicas da ATL. ${ }^{57}$

A morfologia da lesão cutânea na ATL pode guardar relação com o aspecto da histologia e também com o prognóstico. ${ }^{47}$ Yamaguchi e colaboradores ${ }^{58}$ encontraram tempo médio de sobrevida de nove meses para pacientes com lesões nodulares, 11 meses para aqueles com pápulas e 32 meses para os que tinham eritema. O exame histopatológico da pele dos pacientes com ATL pode ser indistinguível da MF, mostrando densos infiltrados de células pleomórficas (linfócitos atípicos), que ocupam a derme e podem chegar ao subcutâneo. O infiltrado, que pode ser superficial ou mais difuso, consiste de células $\mathrm{T}$ de tamanho médio ou grande, exibindo núcleos pleomórficos ou polilobulados com epidermotropismo marcante. $\mathrm{Na}$ forma indolente observa-se infiltrado dérmico esparso com células mostrando poucas atipias. ${ }^{56} \mathrm{O}$ padrão de linfoma de célula $\mathrm{T}$ periférica predomina, mas não é exclusivo, sendo descritos outros padrões. ${ }^{59}$

O prognóstico depende da variante clínica da ATL. Nas formas agudas e linfomatosas a sobrevida média varia de duas semanas a mais de um ano. Nas formas crônicas e indolentes o curso é mais protraído, sendo a sobrevida mais longa. No entanto, pode ocorrer a transformação para a forma aguda, com curso agressivo. Causas de óbito na ATL incluem as infecções como pneumonia por Pneumocystis jirovecii, herpes-zóster disseminado, meningite criptocócica, além de hipercalcemia e coagulação intravascular disseminada. ${ }^{33,56}$

\section{Manifestações dermatológicas na HAM/TSP}

A HAM/TSP é mielopatia grave e incapacitante, de início insidioso, que compromete o controle vesical, acarreta distúrbios sensoriais e paraparesia espástica lentamente progressiva. ${ }^{30}$ Predomina em adultos do sexo feminino, embora seja relatada em crianças e adolescentes. ${ }^{6,26,30}$ É relacionada com transmissão por via sexual no adulto e com carga proviral aumentada. ${ }^{6}$ O risco para desenvolvê-la ao longo da vida é estima- 
do entre 0,3 e $4 \%$ dos infectados. ${ }^{\top}$ Caracteriza-se por resposta de imunidade celular pro-inflamatória exagerada, com produção de IFN- $\gamma$ e TNF- $\alpha$, possivelmente aliada a condicionamento genético. ${ }^{7}$ Lesões de pele já foram descritas em associação com a HAM/TSP: xerodermia, eritema palmar e malar foram observados em pacientes japoneses. ${ }^{60}$ Os quadros de xerose cutânea são os mais freqüentemente associados à doença ${ }^{61}$ (Figura 3). Estudo brasileiro demonstrou freqüência aumentada de dermatofitoses (onicomicose), xerose, dermatite seborréica, eritema palmar e candidíase no grupo de doentes, contudo a associação significativa foi para xerose, candidíase cutânea e eritema palmar. No mesmo estudo outras alterações descritas foram: eczema crônico, reações por drogas, fotossensibilidade, escabiose, verrugas, foliculite decalvante, eritema nodoso, vitiligo e molusco contagioso. ${ }^{61}$ Ictiose adquirida de caráter moderado a grave foi encontrada em $43 \%$ de um grupo de pacientes avaliados em outro estudo. ${ }^{62}$ Enquanto a candidíase poderia ser explicada pela perda do controle esfincteriano, ${ }^{61}$ as alterações xeróticas e a ictiose adquirida não têm seu mecanismo completamente esclarecido. ${ }^{17}$ Alterações autonômicas com redução da resposta simpática na pele são descritas nos indivíduos com HAM/TSP, mas o dano direto na pele pelo linfócito infectado poderia estar implicado na gênese da xerose ${ }^{61} \mathrm{~A}$ ativação de queratinócitos foi demonstrada por Milagres e colaboradores, ${ }^{62}$ que admitem o papel de citocinas produzidas por linfócitos infectados nesse processo. A associação da DI com HAM/TSP já foi comentada..$^{30}$ A Organização Mundial de Saúde inclui nos critérios para o diagnóstico da HAM/TSP manifestações sistêmicas não neurológicas, que podem estar associadas, e entre elas a síndrome de Sjögren, ictiose, vasculites e ATL. ${ }^{63}$

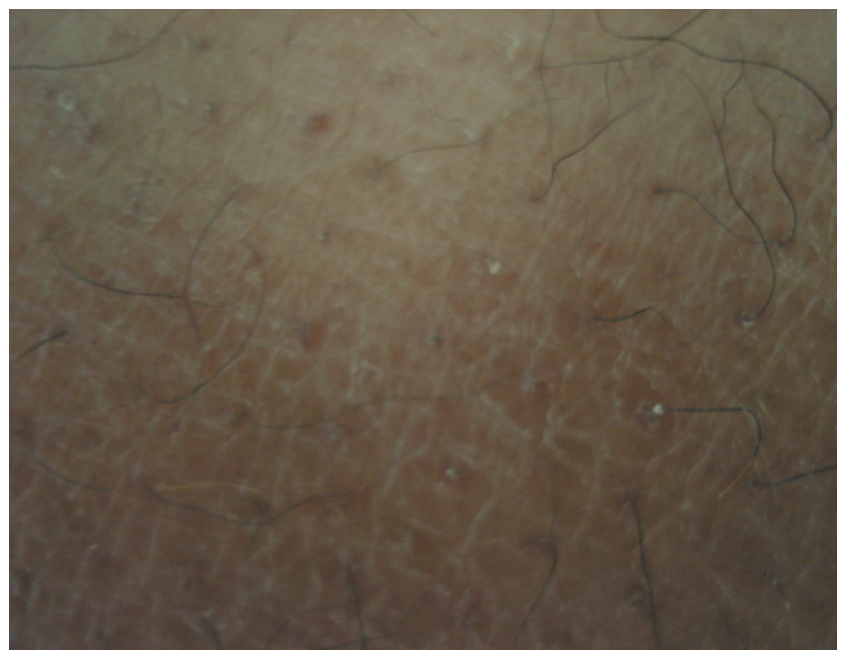

Figura 3: Ictiose adquirida em indivíduo com HAM/TSP

\section{Manifestações dermatológicas em indivíduos assintomáticos soropositivos para o HTLV-1}

Além das várias manifestações cutâneas observadas na ATL e na HAM/TSP, existem evidências de que lesões dermatológicas podem estar associadas à infecção pelo HTLV-1 em indivíduos assintomáticos ${ }^{17,64}$ (Quadro 2).

Em estudo transversal feito em candidatos à doação de sangue, Gonçalves e colaboradores ${ }^{18}$ encontraram alterações da pele predominando significativamente no grupo de soropositivos assintomáticos para o HTLV-1 quando comparado ao grupo controle soronegativo. Dermatofitoses, dermatite seborréica e ictiose adquirida foram associadas à soropositividade (Figura 4). A detecção do provírus na lesão, utilizando-se a técnica de PCR, foi mais freqüente nos espécimes de pele com lesão do que na pele normal, controle pareado, do mesmo paciente.$^{18}$ Outro estudo transversal feito em três gerações de família com alta prevalência de infecção pelo HTLV-1 demonstrou a relação entre a infecção e o achado de lesões cutâneas, especialmente as relacionadas à xerose. ${ }^{65}$

Tem sido relatado que pacientes atendidos em clínicas dermatológicas, com ênfase ou não em tratamento de doenças de transmissão sexual, têm maior prevalência da infecção pelo HTLV-1 do que a observada na população em geral. ${ }^{66-68} \mathrm{~A}$ ocorrência de DA e DS foi significativamente associada à infecção pelo HTLV-1 na Jamaica. ${ }^{69}$ A DS foi associada à alta carga proviral em crianças, enquanto a DA não mostrou tal associação ${ }^{28}$ Posteriormente a DA foi observada em 16 crianças dessa mesma coorte, e foi relacionada a aumento da carga proviral por um ano depois do ponto de estabilização dos títulos de anticorpos, sugerindo expansão de clones de células infectadas. Os autores aventam a possibilidade de que essa expansão clonal possa ser um marcador para doença relacionada ao HTLV-1 na idade adulta. ${ }^{70}$

A associação da escabiose com a infecção pelo HIV e pelo HTLV-1 é bem conhecida. ${ }^{71}$ Em países cuja prevalência da infecção pelo HTLV-1 é alta, a escabiose crostosa (EC) é um marcador dessa infecção. A EC tem características psoriasiforme e verrrucosa nas

QUADro 2: Lesões dermatológicas em indivíduos assintomáticos portadores de HTLV-1

Dermatofitoses

Dermatite seborréica (DS)

Ictiose adquirida

Xerose

Dermatite atópica (DA)

Escabiose

Escabiose crostosa (EC) 


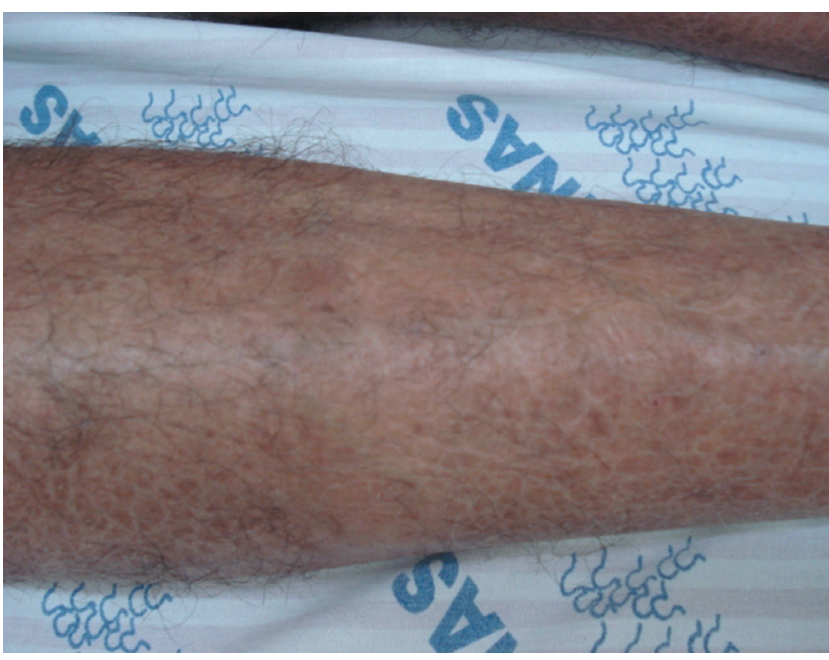

Figura 4: Ictiose adquirida em indivíduo soropositivo assintomático

mãos e pés, com hiperqueratose das unhas, eritema e descamação envolvendo face, couro cabeludo e tronco (Figura 5). Pode ainda estar localizada exclusivamente em face, mão, pé, pododáctilo ou região plantar. $\mathrm{O}$ prurido pode ser mínimo. ${ }^{71}$ As causas descritas para esse tipo de escabiose são: supressão da resposta celular T (como na infecção pelo HIV, HTLV-1, ATL e transplantados), diabetes, várias neuropatias (incluindo a hanseníase), artrite reumatóide, lúpus eritematoso sistêmico e desnutrição. Nos indivíduos sem fatores identificados para imunossupressão é possível que o quadro seja decorrente de resposta imune do tipo Th2.$^{53}$ Interessante salientar que a EC tem sido relatada na HAM/TSP61, ${ }^{72}$ condição conhecida pela grande produção de citocinas pró-inflamatórias, mas que tem também títulos aumentados de anticorpos. ${ }^{7}$ Em 78 casos de EC estudados na Austrália,

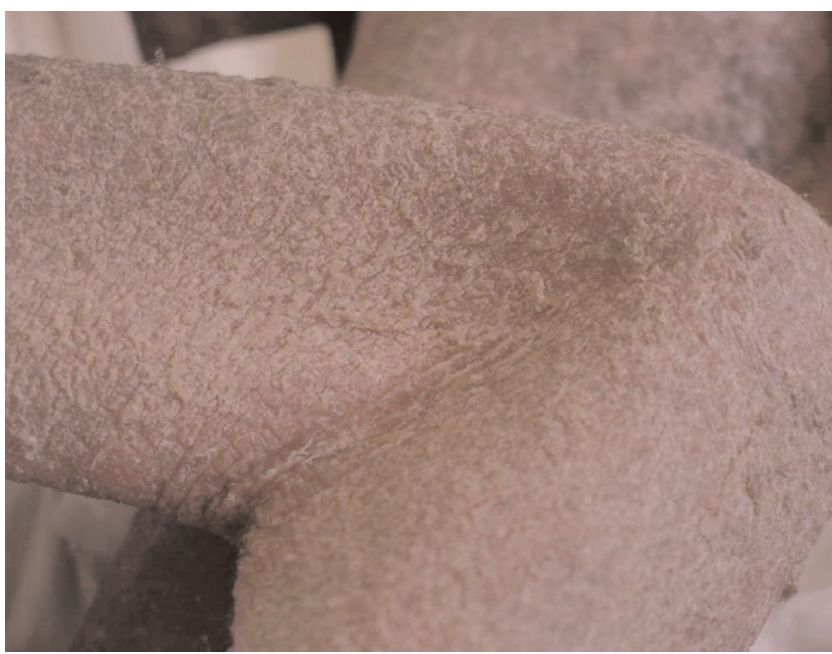

FiguRA 5: Escabiose crostosa: eritema e descamação exuberantes detalhe do membro inferior

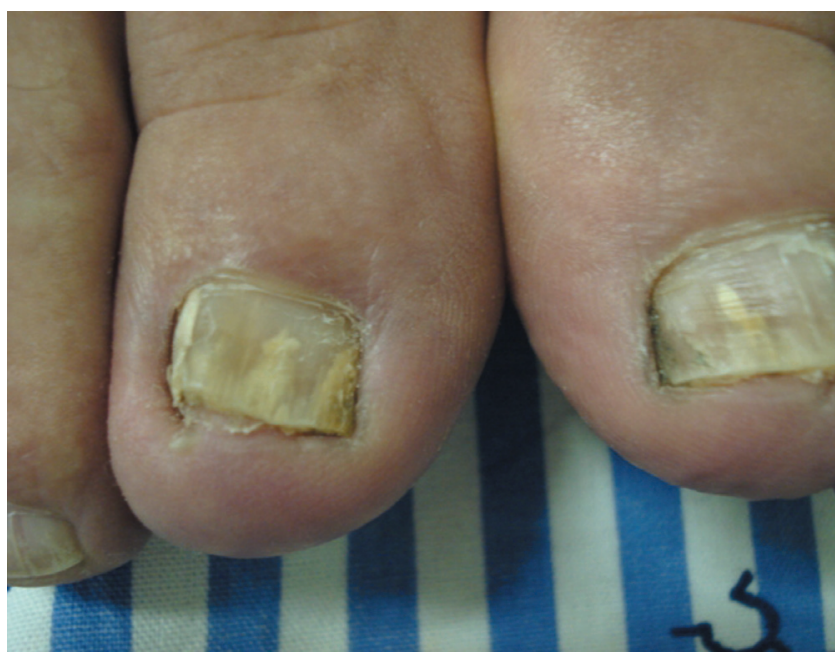

FIGURA 6: Dermatofitose: onicomicose nos háluxes

observou-se aumento de IgE em 96\% e eosinofilia em $58 \%$. Nesse estudo, fatores de risco para imunossupressão estavam presentes em mais da metade dos casos, incluindo três pacientes com infecção por HTLV-1. ${ }^{53}$ Em estudo de 91 casos de escabiose na Bahia, Brites e colaboradores ${ }^{73}$ encontraram $32 \%$ dos casos associados à infecção por HTLV-1 e $20 \%$ em coinfectados por HIV/HTLV-1. Escabiose crostosa foi preditiva da co-infecção HIV/HTLV-1 e pareceu estar associada à imunodeficiência grave e ao óbito. Nenhum caso de ATL foi observado, em seguimento de dois anos. Formas graves de escabiose (mais de $80 \%$ do corpo com lesões, mas sem todas as características de EC) foram fortemente associadas com infecção por HTLV-1.73 No Peru, 23 casos de EC foram testados para HTLV-1, resultando em $69,9 \%$ de soropositividade. Dos 16 soropositivos, um caso de ATL e quatro

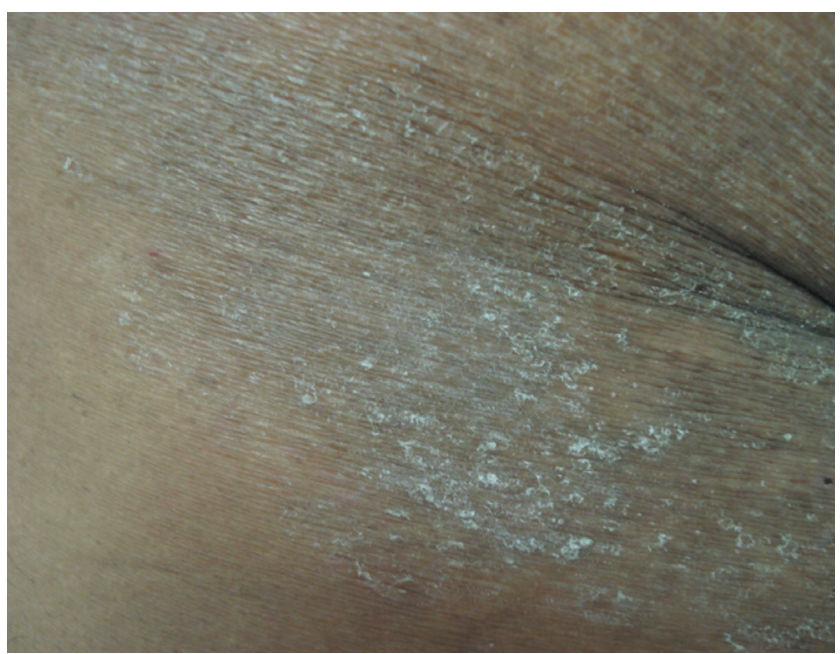

FIgURA 7: Dermatofitose: tinha do corpo extensa, descamação e hipercromia 
com HAM/TSP foram observados.Todos os demais eram infectados assintomáticos, incluindo três casos com infestações recidivantes que resultaram em dois óbitos.72 Relatos de casos de EC associados a tinhas também foram descritos em indivíduos soropositivos assintomáticos. ${ }^{74,75}$

As micoses superficiais podem ter sua clínica modificada pela imunossupressão não só na morfologia e extensão das lesões como também na evolução. ${ }^{54}$ Formas graves, invasivas de infecção foram descritas na ATL. ${ }^{54}$ Onicomicoses foram observadas em casos de HAM/TSP, sem associação significativa ${ }^{61}$ As dermatofitoses foram associadas à condição de soropositividade, especialmente a tinha dos pés ${ }^{18,64}$ (Figuras 6 e 7).

\section{REFERÊNCIAS}

1. Kroon EG, Carneiro-Proietti ABF. Vírus linfotrópicos de células T humanas tipos 1 e 2 (HTLV-1/2) - histórico, estrutura e ciclo de multiplicação viral. In: CarneiroProietti ABF,org. HTLV. Belo Horizonte: Fundação Centro de Hematologia e Hemoterapia de Minas Gerais; 2006. p.11-20.

2. Poiesz BJ, Ruscetti FW, Gazdar AF, Bunn PA, Minna JD, Gallo RC. Detection and isolation of type $\mathrm{C}$ retrovirus particles from fresh and cultured lymphocytes of a patient with cutaneous T-cell lymphoma. Proc Natl Acad Sci USA. 1980;77:7415-19.

3. Gessain A, Barin F, Vernant JC, Gout O, Maurs L, Calender A, et al. Antibodies to human T-lymphotropicvirus type-I in patients with tropical spastic paraparesis. Lancet. 1985;326:407-10.

4. Mochizuki M, Watanabe T, Yamaguchi K, Yoshimura K, Nakashima S, Shirao M, et al.Uveitis associated with human T-cell lymphotropic virus type I. Am J Ophthalmol. 1992;114:123-9.

5. LaGrenade L, Hanchard B, Fletcher V, Cranston B, Blattner W. Infective dermatitis of Jamaican children: a marker of HTLV-I infection. Lancet. 1990;336:1345-7.

6. Proietti FA, Carneiro-Proeitti AB, Catalan-Soares BC, Murphy EL. Global epidemiology of HTLV-I infection and associated diseases. Oncogene. 2005;24:6058-68.
O encontro de lesões de pele em soropositivos assintomáticos pode ter relevância para o diagnóstico da infecção pelo HTLV-1 e na abordagem de lesões recidivantes ou refratárias ao tratamento convencional. ${ }^{64} \mathrm{Em}$ um país de dimensões continentais, com grande fluxo migratório de populações e que tem áreas conhecidamente endêmicas para a infecção pelo HTLV-1, é da maior importância a atenção do dermatologista para fazer a investigação em pacientes com ictiose adquirida sem causa aparente, EC, dermatofitoses e DS atípicas ou de difícil controle, e em crianças com eczemas extensos refratários ou que tenham critérios para diagnóstico de DI.

\section{AGRADECIMENTOS}

Ao GIPH (Grupo Interdisciplinar de Pesquisas em HTLV) pelo suporte técnico-científico em todas as etapas do projeto do qual faz parte esta revisão.
7. Verdonck K, Gonzaléz E, Van Doreen S, Vandamme AM, Vanham G, Gottuzzo E. Human T-lymphotropic virus 1: recent knowledge about an ancient infection. Lancet Infect Dis. 2007;7:266-81.

8. Carneiro-Proietti ABF, Ribas JGR, Catalan-Soares BC, Martins ML, Brito-Melo GEA, Martins-Filho OA, et al. Infecção e doença pelos vírus linfotrópicos humanos de células T (HTLV-I/II) no Brasil. Rev Soc Bras Med Trop. 2002;35:499-508.

9. Carneiro-Proietti ABF, Catalan-Soares B, Proietti FA, GIPH (Interdisciplinary HTLV-I/II Research Group). Human T Cell Lymphotropic Viruses (HTLV-I/II) in South America: Should it be a Public Health Concern? J Biomed Sci. 2002;9:587-95.

10. Catalan-Soares B, Carneiro-Proietti ABF, Proietti FA, Interdisciplinary HTLV Research Group. Heterogeneous geographic distribution of human T-cell lymphotropic viruses I and II (HTLV-I/II): serological screening prevalence rates in blood donors from large urban areas in Brazil. Cad Saude Publica. 2005;21:926-31.

11. Bangham CR. The immune control and cell-to-cell spread of human T-lymphotropic virus type 1 . J Gen Virol. 2003;84:3177-89.

12. Koralnik IJ, Boeri E, Saxinger WC, Monico AL, Fullen J, Gessain A et al. Phylogenetic associations of human and 
simian T-cell leukemia/lymphotropic virus type I strains: evidence of interspecies transmission. J Virol.1994;68:2693-707.

13. Bittencourt AL. Vertical transmission of HTLV-I/II: a review. Rev Inst Med Trop Sao Paulo. 1998;40:245-51.

14. Catalan-Soares BC, Proietti FA. HTLV-1 e 2: aspectos epidemiológicos. In: Carneiro-Proietti ABF,org. HTLV Belo Horizonte: Fundação Centro de Hematologia e Hemoterapia de Minas Gerais; 2006. p.69-85.

15. Manns A, Wilks RJ, Murphy EL, Haynes G, Figueroa JP, Barnett M, et al. A prospective study of transmission by transfusion of HTLV-I and risk factors associated with seroconversion. Int J Cancer. 1992;51:886-91.

16. Sabino EC, Carvalho SMF. Diagnóstico laboratorial do HTLV. In: Carneiro-Proietti ABF,org. HTLV. Belo Horizonte: Fundação Centro de Hematologia e Hemoterapia de Minas Gerais; 2006.p.61-8.

17. NobreV, Guedes ACM, Proietti FA, Stanciolli E, Martins ML, Serufo JC, et al. Lesões dermatológicas em pacientes infectados pelo vírus linfotrópico humano de células T do tipo 1 (HTLV-1). Rev Soc Bras Med Trop. 2005;38:43-52.

18. Gonçalves DU, Guedes AC, Proietti AB, Martins ML, Proietti FA, Lambertucci JR, et al. Dermatologic lesions in assymptomatic blood donors seropositive for human T cell lymphotropic virus type-1. Am J Trop Med Hyg. 2003;68:562-5.

19. LaGrenade L. Manifestações dermatológicas do HTLV-1. In: Carneiro-Proietti ABF, editor. HTLV-I / HTLV-II. Belo Horizonte: Fundação Centro de Hematologia e Hemoterapia de Minas Gerais; 2000. p. 139-146.

20. Sweet RD. A pattern of eczema in Jamaica. $\mathrm{Br} J$ Dermatol.1966;78:93-100.

21. Gonçalves DU, Guedes ACM, Carneiro-Proietti ABF, Lambertucci JR. HTLV-I associated infective dermatitis may be an indolent HTLV-I associated lymphoma. Braz J Infect Dis. 2000;4:100-2.

22. Pérez CL, Villarroel BJ, Reyes JA, Benavides MA, Muñoz OC. Exfoliative erythroderma and infective dermatitis in an infant infected with human T-lymphotropic virus type I (HTLV I). Rev Chilena Infectol. 2007;24:142-8.

23. Bittencourt AL, Oliveira MF, Ferraz N, Vieira MG, Muniz A, Brites C. Adult-onset infective dermatitis associated with HTLV-I. Clinical and immunopathological aspects of two cases. Eur J Dermatol. 2006;16:62-6.

24. La Grenade L, Manns A, Fletcher V, Carberry C, Hanchard B, Maloney EM, et al. Clinical, pathologic, and immunologic features of human T-lymphotrophic virus type I-associated infective dermatitis in children. Arch Dermatol. 1998;134:439-44.

25. Oliveira MF, Brites C, Ferraz N, Magalhães P, Almeida F, Bittencourt AL. Infective dermatitis associated with the human T-cell lymphotropic virus type $\mathrm{I}$ in Salvador, Bahia, Brazil. Clin Infect Dis. 2005;40:90-6.

26. Bittencourt AL, Primo J, Oliveira MF. Manifestations of the human T-cell lymphotropic virus type I infection in childhood and adolescence. J Pediatr. 2006;82:411-20.

27. Lenzi MER, Araújo AQC, Cuzzi-Maya T, Serapião MJ, Leite ACB, Schorr D, et al. Dermatite infectiva associada ao HTLV-I: relato de caso. An Bras Dermatol.
1996;71:115-18.

28. Maloney EM, Nagai M, Hisada M, Soldan SS, Goebel PB, Carrington $M$, et al. Prediagnostic human $T$ lymphotropic virus type I provirus loads were highest in Jamaican children who developed seborrheic dermatitis and severe anemia. J Infect Dis. 2004;189:41-5.

29. Bittencourt AL, Oliveira MF, Brites C, Van Weyenbergh J, da Silva Vieira MG, Araújo I. Histopathological and immunohistochemical studies of infective dermatitis associated with HTLV-I. Eur J Dermatol. 2005;15:26-30.

30. Primo JRL, Brites C, Oliveira MFS, Moreno-Carvalho O, Machado $\mathrm{M}$, Bittencourt AL. Infective dermatitis and Human T-cell lymphothropic virus type 1-associated myelopathy/tropical spastic paraparesis in childhood and adolescence. Clin Infect Dis. 2005;41:535-41.

31. Pombo-de-Oliveira MS, Dobbin JA, Loureiro P, Borduchi D, Maia RC, Fernandes MA, et al. Genetic mutation and early onset of T-cell leukemia in pediatric patients infected at birth with HTLV-1. Leukemia Res. 2002;26:155-61.

32. Hanchard B. Outcomes of Early Life Exposure to Human T Cell Lymphotropic Virus type I. Clin Infec Dis. 2005; $41: 543$.

33. Lopes MSN, Dobbin JA. Leucemia/linfoma de células T do Adulto (ATL): um protótipo de doença viral em hematologia. In: Carneiro-Proietti ABF, org. HTLV. Belo Horizonte: Fundação Centro de Hematologia e Hemoterapia de Minas Gerais;2006.p.93-114.

34. Dummer R, Asagoe K, Cozzio A, Burg G, Doebbeling U, Golling P, Fujii K, Urosevic M. Recent advances in cutaneous lymphomas. J Dermatol Sci. 2007;48:157-67.

35. Sanches JA Jr, Moricz CZM, Neto CF. Processos linfoproliferativos da pele. Parte 2 - Linfomas cutâneos de células T e de células NK. An Bras Dermatol. 2006;81:7-25.

36. Shohat M, Shohat B, Mimouni D, Pauli G, Ellerbrok H, David $\mathrm{M}$, et al. Human T-cell lymphotropic virus type 1 provirus and phylogenetic analysis in patients with mycosis fungoides and their family relatives. $\mathrm{Br} \mathrm{J}$ Dermatol. 2006;155:372-8.

37. Pancake BA, Wassef EH. Zucker-Franklin D. Demonstration of antibodies to human T-cell lymphotropic virus- 1 tax in patients with the cutaneous T cell lymphoma, mycosis fungoides, who are seronegative for antibodies to the structural proteins of the virus. Blood. 1996;88:3004-9.

38. Zucker-Franklin D, Pancake BA, Najfeld V. Localization of HTLV-I tax proviral DNA in mononuclear cells. Blood Cells Mol Dis. 2003;31:1-6.

39. Zucker-Franklin D, Kosann MK, Pancake BA, Ramsay DL, Soter NA. Hypopigmented mycoses fungoides associated with human T cell lymphotropic virus type I tax in a pediatric patient. Pediatrics. 1999;103:1039-44.

40. Wood GS, Salvekar A, Schaffer J, Crooks CF, Henghold W, Fivenson DP, et al. Evidence against a role for human T-cell lymphotrophic virus type I (HTLV-I) in the pathogenesis of American cutaneous T-cell lymphoma. J Invest Dermatol. 1996;107:301-7.

41. Wood GS, Schaffer JM, Boni R, Dummer R, Burg G, Takeshita M, et al. No evidence of HTLV-I proviral integration in lymphoproliferative disorders associated 
with cutaneous T-cell lymphoma. Am J Pathol. 1997; 150:667-73.

42. Lisby G, Reitz MS Jr, Vejlsgaard GL. No detection of HTLV-I DNA in punch skin biopsies from patients with cutaneous T-cell lymphoma by the polymerase chain reaction. J Invest Dermatol. 1992;98:417-20.

43. Böni R, Davis-Daneshfar A, Burg G, Fuchs D, Wood GS. No detection of HTLV-I proviral DNA in lesional skin biopsies from Swiss and German patients with cutaneous T-cell lymphoma. Br J Dermatol. 1996; 134:282-4.

44. Pombo de Oliveira MS, Loureiro P, Bittencourt A, Chiattone C, Borduchi D, Carvalho SMF, et al. Geographic diversity of adult T-cell leukemia lymphoma in Brazil. The Brazilian ATLL Study Group. Int J Cancer. 1999;83:291-8.

45. Farias de Carvalho SM, Pombo de Oliveira MS, Thuler LC, Rios M, Coelho RC, Rubim LC, et al. HTLV-I and HTLV-II infections in hematologic disorder patients, cancer patients, and healthy individuals from Rio de Janeiro, Brazil. J Acquir Immune Defic Syndr Hum Retrovirol. 1997;3:238-42.

46. Pombo-de-Oliveira MS, Carvalho SM, Borduchi D, Dobbin JA, Salvador J, Correa RB, et al. Adult T-cell leukemia/lymphoma and cluster of HTLV-I associated diseases in Brazilian settings. Leuk Lymphoma. 2001;42:135-44.

47. Ohshima K. Pathological features of diseases associated with human T-cell leukemia virus type I. Cancer Sci. 2007;98:772-8.

48. Pombo-de-Oliveira MS, Loureiro P, Carvalho SMF. Leucemia/Linfoma de células $\mathrm{T}$ do adulto (ATLL): características clínico - patológicas e apresentação no Brasil. In: Carneiro-Proietti ABF, editor. HTLV-I / HTLV-II. Belo Horizonte: Fundação Centro de Hematologia e Hemoterapia de Minas Gerais; 2000. p. 76-107.

49. Bangham CRM, Osame M. Cellular immune response to HTLV-1. Oncogene. 2005;24:5035-45.

50. Oliveira MF, Primo JRL, Rebouças ATS, Ferraz N, Bittencourt AL. Forma inicial de linfoma em adolescente com mielopatia e dermatite infecciosa associadas ao HTLV-I. An Bras Dermatol. 2005;80:S241-2.

51. Gabet AS, Mortreux F, Talarmin A, Plumelle Y, Leclercq I, Leroy A, et al. High circulating proviral load with oligoclonal expansion of HTLV-1 bearing $\mathrm{T}$ cells in HTLV-1 carriers with strongyloidiasis. Oncogene. 2000; 19:4954-60.

52. Bittencourt AL. Adult T-cell leukemia/lymphoma (ATL) in Bahia, Brazil. Braz J Infect Dis. 2005;9:437-8.

53. Roberts LJ, Huffam SE, Walton SF, Currie BJ. Crusted scabies: clinical and immunological findings in seventy-eight patients and a review of the literature. J Infec.2005;50:375-81.

54. Grossman ME, Pappert AS, Garzon MC, Silvers DN. Invasive Trychopbyton rubrum infection in the immunocompromised host: report of three cases. J Am Acad Dermatol.1995;33:315-18.

55. Levine PH, Cleghorn F, Manns A, Jaffe ES, NavarroRoman L, Blattner WA, et al. Adult T-cell leukemia/ lymphoma: a working point-score classification for epidemiological studies. Int J Cancer. 1994;59:491-3.

56. Willenze R, Jaffe ES, Burg G, Cerroni L, Berti E, Swerdlow SH, et al. Who-Eortc classification for cutaneous lymphomas. Blood. 2005;105:3768-85.

57. Okada J, Imafuku S, Tsujita J, Moroi Y, Urabe K, Furue M. Case of adult T-cell leukemia/lymphoma manifesting marked purpura. J Dermatol. 2007;34:782-5.

58. Yamaguchi T, Ohshima K, Karube K, Tutiya T, Kawano $\mathrm{R}$, Suefuji $\mathrm{H}$, et al. Clinicopathological features of cutaneous lesions of adult T-cell leukaemia/ lymphoma. Br J Dermatol. 2005; 152:76-81.

59. Bittencourt AL, Barbosa HS, Carvalho BAC, Ferraz N, Brittes C. Leucemias/linfomas de células $\mathrm{T}$ do adultoprimários da pele na Bahia: achados clínico-patológicos e imuno-histoquímicos. An Bras Dermatol. 2005; 80: S246-7.

60. Hashiguchi T, Osame M, Arimura K, Fijiyama J, Furukawa Y, Kubota R, et al. Skin manifestations in HTLV-I-associated myelopathy (HAM): xerosis and erythema. In: Róman CG, Vernant JC, Osame M, editors. HTLV-I and the Nervous System. New York: Alan R;1989. p. 443-8.

61. Lenzi MER, Cuzzi-Maia T, Oliveira LA, Andrada-Serpa MJ, Araújo AQ. Dermatological findings of human T lymphotropic virus type 1 (HTLV-I)-associated myelopathy/ tropical spastic paraparesis. Clin Infec Dis. 2003;36:507-13.

62. Milagres SP, Sanches JA Jr, Milagres AC, Valente NY. Histopathological and immunohistochemical assessment of acquired ichthyosis in patients with human T-cell lymphotropic virus type I-associated myelopathy. Br J Dermatol. 2003;149:776-81.

63. Castro-Costa CM, Araújo AQC, Barreto MM, Takayanagui OM, Sohler MP, Silva ELM, et al. Proposal for diagnostic criteria of tropical spastic paraparesis/HTLV-I-associated myelopathy (TSP/HAM). AIDS Res Hum Retroviruses. 2006;22:931-35.

64. Gonçalves DU. Manifestações dermatológicas em doadores de sangue com sorologia alterada para o vírus linfotrópico humano de células T- tipo 1 em Minas Gerais, Brasil [Tese]. Belo Horizonte (MG): Universidade Federal de Minas Gerais; 2000. 158 p.

65. Nobre V, Guedes AC, Martins ML, Barbosa-Stancioli EF, Serufo JC, Proietti FA, et al. Dermatological findings in 3 generations of a family with a high prevalence of human $\mathrm{T}$ cell lymphotropic virus type 1 infection in Brazil. Clin Infect Dis. 2006;43:1257-63.

66. Nobre V, Guedes AC, Proietti FA, Martins ML, Nassif G, Serufo JC, et al. Increased prevalence of human $\mathrm{T}$ cell lymphotropic virus type 1 in patients attending a Brazilian dermatology clinic. Intervirology. 2007;50:316-18.

67. Olumide YM, Dada AJ, Sogbanmu IB, Aruna GA. Seroprevalence study of HIV-I, HIV-II and HTLV-I among patients at the Dermato-Venereology Clinic of the Lagos University Teaching Hospital. Int J Dermatol. 1997;36:741-4.

68. Ajithkumar K, Ramalingam S, Kannangai R, Prakash KJ. Human T lymphotrophic virus-I (HTLV-I) infection in patients with unclassifiable dermatitis in central Kerala, south India: a preliminary study. Sex Transm Infect. 2002;78:434.

69. Maloney EM, Wiktor SZ, Palmer P, Cranston B, Pate EJ, 
Cohn S, et al. A cohort study of health effects of human T-cell lymphotropic virus type $I$ infection in Jamaican children. Pediatrics. 2003;112:136-42.

70. Maloney EM, Yamano Y, VanVeldhuisen PC, Sawada T, Kim N, Cranston B, et al. Natural history of viral markers in children infected with human $T$ lymphotropic virus type $\mathrm{I}$ in Jamaica. J Infect Dis. 2006; 194:552-60.

71. Chosidow O. Scabies and pediculosis. Lancet. 2000;355:819-26.

72. Blas M, Bravo F, Castillo W, Castillo WJ, Ballona R, Navarro P, et al. Norwegian scabies in Peru: the impact of human T cell lymphotropic virus type I infection. Am
J Trop Med Hyg. 2005;72:855-7.

73. Brites C, Weyll M, Pedroso C, Badaró R. Severe and Norwegian scabies are strongly associated with retroviral (HIV-1/HTLV-1) infection in Bahia, Brazil. AIDS. 2002;16:1292-3.

74. Cordoliani F, Vasseur E, Baccard M, Fournier S, Feuilhade de Chauvin M, Tancrede E, et al. Ivermectinresponsive crusted scabies in HTLV1 carrier. Dermatology. 1996;192:351-2.

75. Daisley H, Charles W, Suite M. Crusted (Norwegian) scabies as a pre-diagnostic indicator for HTLV-1 infection. Trans R Soc Trop Med Hyg.1993;87:295.

ENDEREÇO PARA CORRESPONDÊNCIA / MAILING ADDRESS: Marcelo Grossi Araújo Depto. Clínica Médica da Fac. Medicina da UFMG Av. Prof. Alfredo Balena 190/246.

$30130100 \quad$ Belo Horizonte - MG

Tel/fax: (31) 3241-6941

E-mail:mgrossi@medicina.ufmg.br

Como citar este artigo/How to cite this article: Araújo MG, Gonçalves DU, Carneiro-Proietti ABF, Proietti FA, Guedes ACM. Manifestações cutâneas em indivíduos infectados ou com doenças relacionadas ao vírus linfotrópico de células T humanas do tipo 1. An Bras Dermatol. 2008;83(5):393-407. 
1. Em relação ao diagnóstico da infecção por HTLV-1 assinale a afirmativa INCORRETA:

a. O teste de Western Blott permite diferenciar a infecção do vírus do tipo1 daquela causada pelo vírus do tipo 2 .

b. O teste de triagem sorológica é feito por ensaio imunoenzimático e pode gerar resultados falso-positivos.

c. A reação em cadeia da polimerase (PCR) não pode ser utilizada para o diagnóstico devido à propriedade de esse vírus integrar-se ao DNA da célula do hospedeiro.

d. Entre as causas de reações sorológicas consideradas indeterminadas por ensaio imunoenzimático, estão a imunossupressão e a infecção pelo HTLV-2.

2. São características do vírus linfotrópico de células T humanas tipo 1 (HTLV-1), EXCETO:

a. Foi o primeiro retrovírus associado a doença humana.

b. O aumento da carga proviral ocorre predominantemente pela expansão clonal de linfócitos infectados.

c. Diferente do vírus da imunodeficiência humana, não existe atividade da enzima transcriptase reversa no HTLV-1.

d. Acredita-se que baixa variabilidade da seqüência do HTLV-1 intra e inter-individual seja decorrente da maneira de disseminação do HTLV.

3. Em relação à distribuição do HTLV-1 é INCORRETO afirmar:

a. É prevalente no Caribe, África, América do Sul e sul do Japão.

b. O Brasil é país endêmico, com prevalência distribuída uniformemente entre as regiões.

c. Admite-se que o Brasil seja o país com o maior número de infectados.

d. Estima-se entre 15 e 20 milhões o número de infectados no mundo.

4. Sobre a transmissão do HTLV-1, assinale a afirmativa INCORRETA:

a. Considerando-se a via sexual, é mais eficiente na direção da mulher para o homem.

b. Sexo sem proteção, múltiplos parceiros, úlceras genitais e sexo pago estão relacionados com a via de transmissão sexual.

c. Componentes de sangue infectado ou compartilhamento de agulhas entre usuários de drogas endovenosas estão relacionados à via parenteral. d. A amamentação é a principal forma de transmissão na direção mãe-filho.

5. Ainda sobre a transmissão do HTLV-1, é CORRETO afirmar:

a. A adoção da triagem em bancos de sangue em vários países não reduziu o número de novas infecções.

b. A transmissão por via endovenosa é a mais eficiente, ocorrendo a soroconversão em percentual que varia de 40 a $60 \%$ dos expostos ao sangue contaminado.

c. A soroconversão se dá em torno de $\mathbf{1 8 0}$ dias depois da exposição, por via endovenosa, a componentes de sangue contaminado.

d. Carga proviral materna e tempo de aleitamento não estão relacionados à transmissão materno-infantil.

6. Sobre as manifestações cutâneas relacionadas ao HTLV-1 é INCORRETO afirmar:

a. Só recentemente as lesões de pele foram relacionadas à infecção pelo HTLV-1, nos casos de leucemia/linfoma de células $\mathrm{T}$ do adulto.

b. Entre os mecanismos propostos para explicar o aparecimento de lesões cutâneas estão a imunossupressão e as alterações neurológicas.

c. Dermatoses em indivíduos soropositivos, sem doenças relacionadas ao HTLV-1, têm sido descritas por diversos autores.

d. Nem todas as alterações dermatológicas descritas podem ser consideradas definitivamente relacionadas à infecção pelo HTLV-1.

7. Sobre a dermatite infecciosa é INCORRETO afirmar: a. Foi descrita há mais de 40 anos, mas só foi definitivamente associada ao HTLV-1 em 1990.

b. Sua prevalência entre os vários países acompanha a distribuição do HTLV-1.

c. No Brasil a maioria dos casos descritos é proveniente da Bahia.

d. Trata-se de dermatose característica da infância.

8. O quadro clínico da dermatite infecciosa tem as características abaixo mencionadas, EXCETO:

a. Dermatite eczematosa recidivante.

b. Pápulas foliculares, pústulas e lesões eritêma-

to-descamativas podem ser observadas.

c. As localizações preferenciais são face, axila e virilha.

d. Ausência de resposta aos antimicrobianos. 
9. Em relação ao diagnóstico diferencial da dermatite infecciosa com outras formas de eczema, como a dermatite atópica e a dermatite seborréica, são importantes os seguintes aspectos, EXCETO:

a. Na dermatite atópica o prurido é mais acentuado.

b. As lesões da dermatite infecciosa são mais exuberantes e fétidas

c. A distribuição das lesões é diferente nas dermatites atópica e infecciosa.

d. A dermatite seborréica, exceto no lactente, é rara na infância.

10. Analise as afirmativas abaixo e assinale aquela que não poderia ser considerada critério maior, segundo La Grenade e colaboradores.

a. Culturas positivas para Staphylococcus aureus e estreptococos $\beta$-hemolíticos na pele ou fossas nasais.

b. Soropositividade para o HTLV-1.

c. Rinorréia crônica sem outros sinais de rinite e/ou lesões crostosas no vestíbulo nasal.

d. Início precoce na infância.

11. Sobre a leucemia/linfoma de células $\mathrm{T}$ do adulto (ATL), são afirmativas corretas, EXCETO:

a. A proteína Tax do HTLV-1 tem efeitos na replicação de células infectadas e é capaz de inibir fatores supressores de tumores.

b. Admite-se que a Tax possa inibir a apoptose e com isso favorecer a transformação maligna de células.

c. Estima-se que dos infectados pelo HTLV-1 apenas um a $5 \%$ desenvolvam ATL.

d. Trata-se de doença de bom prognóstico, quando detectada precocemente.

12. Em relação a aspectos da epidemiologia da leucemia/linfoma de células T do adulto (ATL), analise as afirmativas e assinale a CORRETA:

a. O país com o maior número de casos conhecidos é o Brasil, embora sua real incidência seja desconhecida.

b. Carga proviral e fatores ambientais, tais como modo de transmissão, dose do inóculo e presença de outras infecções, poderiam estar implicados no aparecimento da ATL.

c. Postula-se que a infecção crônica e recorrente por Strongyloides stercoralis observada em muitos indivíduos infectados pelo HTLV-1 poderia ser fator protetor para o aparecimento da ATL. d. Não existe evidência de que a dermatite infecciosa esteja associada com o desenvolvimento futuro de ATL.
13. Embora não seja obrigatório, o comprometimento da pele pode ocorrer em percentuais variáveis no curso da leucemia/linfoma de células $\mathrm{T}$ do adulto (ATL); a esse respeito, assinale a afirmativa INCORRETA: a. A expressão de receptores para quimiocinas e moléculas de adesão difere nas lesões de pele e naquelas de outros órgãos linfóides, sugerindo que elas possam ter papel fundamental na definição do órgão-alvo em cada tipo de ATL.

b. As manifestações cutâneas na ATL podem ser decorrentes da infiltração cutânea pela neoplasia, de alterações inflamatórias ou de imunossupressão.

c. O comprometimento cutâneo ocorre entre 43 e $72 \%$ dos casos de ATL.

d. Entre as diversas formas clínicas da ATL, a cutânea pura é predominante no Brasil.

14. Sobre o comprometimento cutâneo na ATL é correto afirmar, EXCETO:

a. No Brasil, a forma crônica da ATL foi a que teve maior percentual de casos com lesões de pele descritas $(73 \%)$.

b. Na forma aguda, predominam as lesões purpúricas não relacionadas à trombocitopenia.

c. A forma caracterizada como linfoma é a que tem manifestações mais exuberantes, com lesões extensas, do tipo placas, que tendem a se infiltrar formando nódulos e tumorações, além da presença de eritrodermia.

d. Na forma subaguda, indolente ou préleucêmica (smouldering) as lesões de pele geralmente constituem a primeira manifestação clínica e podem preceder por meses ou anos a fase leucêmica aguda.

15. Entre as dermatoses relacionadas à imunossupressão observada no curso da ATL, são descritas com maior freqüência:

a. Escabiose crostosa, herpes zoster disseminado e infecções fúngicas atípicas.

b. Sarcoma de Kaposi, herpes-zóster disseminado e infecções fúngicas atípicas.

c. Infecções por micobactérias do complexo avium-intracellulare (MAC), escabiose crostosa e herpes-zóster disseminado.

d. Herpes-zóster disseminado, escabiose crostosa e tuberculose cutânea. 
16. Sobre a doença neurológica conhecida como mielopatia associada ao HTLV-1/paraparesia espástica tropical (HAM/TSP), assinale a afirmativa INCORRETA: a. O risco estimado para o desenvolvimento dessa enfermidade ao longo da vida de um indivíduo infectado é estimado entre 0,3 e $4 \%$.

b. É relacionada com transmissão do HTLV-1 por via sexual no adulto e com carga proviral aumentada c. Predomina em adultos do sexo masculino, embora seja relatada em crianças e adolescentes. d. Caracteriza-se por resposta de imunidade celular pro-inflamatória exagerada, com produção de interferon- $\gamma$ e TNF- $\alpha$.

17. Em relação às manifestações dermatológicas encontradas em pacientes com mielopatia associada ao HTLV-1/paraparesia espástica tropical (HAM/TSP), assinale a afirmativa INCORRETA:

a. Alterações como xerodermia, eritema palmar e malar foram observadas em pacientes japoneses. b. Os quadros de xerose cutânea são os mais freqüentemente associados à doença, incluindo a ictiose adquirida.

c. Estudos brasileiros têm mostrado além da associação com xerose, a candidíase cutânea e o eritema malar.

d. Outras doenças encontradas, mas sem associação demonstrada estatisticamente foram as onicomicoses e a dermatite seborréica.

18. Entre os mecanismos propostos para o surgimento de dermatoses no curso da mielopatia associada ao HTLV-1/paraparesia espástica tropical (HAM/TSP), são possibilidades consideradas na literatura, exceto:

a. A candidíase poderia ser explicada pela imunossupressão que acompanha a HAM/TSP.

b. Alterações autonômicas com redução da resposta simpática na pele poderiam estar relacionadas aos quadros de xerose.

c. A ativação de queratinócitos e a produção de citocinas por linfócitos infectados podem ser consideradas parte dos mecanismos envolvidos na ictiose adquirida.

d. O dano direto na pele pelo linfócito infectado poderia estar implicado na gênese da xerose.
19. Assinale a afirmativa falsa:

a. A dermatite infecciosa está associada ao desenvolvimento futuro de ATL e HAM/TSP.

b. A possibilidade de infecção por HTLV-1 deve ser considerada em crianças com formas graves e resistentes de eczemas.

c. Estudos têm demonstrado que a escabiose crostosa não pode ser considerada marcador para infecção por HTLV-1.

d. A prevalência da infecção pelo HTLV-1 tem-se mostrado aumentada em clínicas para tratamento de doenças de transmissão sexual e naquelas para atendimento dermatológico geral.

20. Estudos têm demonstrado que indivíduos infectados pelo HTLV-1, e sem doença relacionada, apresentam prevalência aumentada de algumas dermatoses. Analise as afirmativas abaixo e assinale a INCORRETA:

a. A tinha dos pés é uma das dermatofitoses associadas à condição de soropositividade para o HTLV-1.

b. A dermatite atópica foi associada a alta carga proviral em crianças da Jamaica.

c. Dermatofitoses, dermatite seborréica, ictiose adquirida têm sido associadas à soropositividade para o HTLV-1.

d. Dermatite atópica e dermatite seborréica estiveram associadas à infecção pelo HTLV-1 em crianças jamaicanas.

\section{Gabarito}

Criocirurgia com nitrogênio líquido e as dermatoses infecciosas. 2008;83(4):285-98.

$\begin{array}{ll}\text { 1. b } & 11 . \mathrm{d} \\ \text { 2. } \mathrm{a} & 12 . \mathrm{a} \\ \text { 3. } \mathrm{b} & 13 . \mathrm{b} \\ \text { 4. b } & 14 . \mathrm{b} \\ \text { 5. a } & 15 . \mathrm{d} \\ \text { 6. d } & 16 . \mathrm{b} \\ \text { 7. c } & 17 . \mathrm{b} \\ \text { 8. b } & 18 . \mathrm{b} \\ \text { 9. d } & 19 . \mathrm{c} \\ \text { 10. c } & 20 . \mathrm{d}\end{array}$

